\title{
Influence of Confinement by COVID-19 on the Quality of Sleep and the Interests of University Students
}

Iratxe Martínez-Lezaun'

Montserrat Santamaría-

Vázquez (1D)

Mario Del Líbano (iD) ${ }^{2}$

'Health Sciences Department, Universidad de Burgos, Burgos, Spain;

${ }^{2}$ Education Sciences Department,

Universidad de Burgos, Burgos, Spain
This article was published in the following Dove Press journal: Nature and Science of Sleep

Purpose: To check for changes in sleep in three temporary times: before COVID-19 lockdown in university students, and also twenty days and forty days afterwards, as well as to see how it has influenced in their daily activities.

Materials and Methods: A longitudinal study was conducted with a sample of 75 participants from different Spanish universities. The Pittsburgh Sleep Quality Index and the Adapted Interest List were administered to evaluate the main variables of the study.

Results: About $70.7 \%$ of the sample showed worse sleep quality at 20 days, almost twice as much as before confinement $(37.3 \%)$, there were more problems falling asleep $(F(2,75)=-3.14, p=$ $0.002)$, and more difficulty getting back to sleep when waking up at night $(F(2.75)=2.08, p=$ 0.037 ) at 40 days of lockdown. In addition, as confinement time went on, students showed less activities. Factors such as working, in addition to studying, and relaxing activities (reading, listening to music) were associated with better sleep quality.

Conclusion: Sleep quality worsened during lockdown in university students, as well as both 20 and 40 days later. Staying busy during the day (not only studying but also working) and spending free time on relaxing activities are related to better sleep quality.

Keywords: lockdown, coronavirus, rest, leisure activities

\section{Introduction}

On March 11th, 2020 the World Health Organization (WHO) ${ }^{1}$ declared the international pandemic situation by COVID-19. To cope with the rapid evolution of the pandemic, a "state of emergency" was decreed in Spain on 14th March 2020, lasting until June 21st, which included a period of quarantine until May 2nd. This measure also included the closure of educational and business centers, and nonessential factories and stores. These measures led to conditions of social distancing and movement limitation, ${ }^{3}$ allowing only activities such as the purchase of basic necessities, travel to health facilities or travel to the workplace. After the end of the quarantine, the Spanish government introduced confinement relief measures, such as the possibility to walk and do exercise at certain times of the day. From that moment on, the country went through different de-escalation phases (from 0 to 3 ) giving way to the "new normality".

The effects of confinement on health have been studied in contexts such as aerospace ${ }^{4}$ or prison. ${ }^{5}$ Also, because of the so-called Hikimori Syndrome, which refers to a voluntary form of social isolation that mainly affects young people. They Santamaría-Vázquez

Health Sciences Department, Universidad de Burgos, Paseo Comendadores $s / n$,

Burgos 0900I, Spain

Tel + 34947 I0954I

Email msvazquez@ubu.es 
live in a room and have no work or academic activity, spending most of their time sleeping or playing video games. This confinement implies the inexistence of physical exercise and the maintenance of a poor diet, which produces various negative effects. On a physical level, it can produce anemia, fragility in the joints, ulcers, etc. On a psychological level, it can reduce social skills to interact, cause insecurity, etc., which reinforces the behavior of staying locked up. ${ }^{6}$

In this sense, confinement implies a decrease in exposure to natural light and an increase in artificial lighting, which according to Wright ${ }^{7}$ can alter a person's internal rhythms, creating complications and deregulating other interrelated aspects such as appetite, mood, energy levels and sleep schedules. In fact, the Society for Behavioral Sleep Medicine published a series of recommendations for managing sleep during the pandemic, ${ }^{8}$ including: creating a sleep routine, trying to maintain a certain level of physical activity and, as far as possible, increasing exposure to natural light. Yadav et al, ${ }^{9}$ also warned of the possibility of increased sleep disorders during confinement and proposed, in addition to the above recommendations, socializing in order to avoid thinking about the pandemic and its consequences.

Physical activity has been shown to have beneficial effects on sleep quality, ${ }^{10}$ and the WHO recommends spending 150 minutes/week on moderate-intensity and 75 minutes/week on high-intensity activities to prevent disease occurrence. ${ }^{11}$ Furthermore, physical activity during confinement was strongly recommended considering that the beneficial effect it has on the immune system could increase protection against COVID-19. ${ }^{12}$

On the other hand, researchers from several countries have studied the psychological consequences of lockdown due to COVID-19, showing that people have a major mental health burden, ${ }^{13}$ with higher levels of distress ${ }^{14}$ and lower psychological well-being ${ }^{15}$

Based on the aforementioned issues, the main objective of this study is to examine whether there were changes in rest and sleep at three time periods: before confinement, at 20 and 40 days of confinement by COVID-19 in university students, as well as to ascertain how this affected their daily activities. We propose the following hypotheses:

Hypothesis $(\mathrm{H}) 1$ : the quality of sleep will be worse during confinement

H2: There will be more trouble sleeping during the first half hour that the person is in bed during confinement
H3: There will be more problems getting back to sleep after waking up during the night in confinement

H4: Students who work will have a better quality of sleep than those who only study during confinement

H5: The number of activities that students will engage in according to their interests will decrease as the confinement progresses

H6: Students who do more physical exercise and relaxing activities after 20 days of confinement will have a better quality of sleep at 40 days.

\section{Materials and Methods Design}

A quasi-experimental design of a longitudinal, quantitative and intra-group type was used. Data were collected at two different time periods: at 20 (time 1, T1) and 40 (time 2, T2) days of confinement.

\section{Sample}

The sample of the study in T1 was composed of 102 participants $(80.4 \%$ women) with the average age of 21.83 ( $\mathrm{SD}=2.97)$. In $\mathrm{T} 2$ there was an experimental attrition rate of $26.4 \%$, resulting in a final sample of 75 people (74.7\% women), with the average age of 21.67 (SD = 2.23). Forty percent belonged to Health Sciences, $25.3 \%$ to Social and Legal Sciences, $17.3 \%$ to Arts and Humanities, $13.3 \%$ to Engineering and Architecture and $4 \%$ to Sciences. $53.3 \%$ were from the fourth year of their degree, $29.3 \%$ from the third year, $13.3 \%$ from the first year and $4 \%$ from the second year. In addition to studying, $40 \%$ also worked before confinement began. None of the participants had psychiatric or respiratory disorders at the time of answering the questionnaires.

A non-probabilistic for convenience sampling was used to obtain the final sample.

\section{Procedure}

An online questionnaire was administered to obtain the sample. Social networks and e-mail were used for its dissemination.

At the beginning of the questionnaire, participants were asked to create a code to match the questionnaires of the two periods and to guarantee anonymity. At the end of the T1 questionnaire, an e-mail was requested in order to send the questionnaire again in $\mathrm{T} 2$. 
The first questionnaire was sent after twenty days of confinement and asked about aspects prior to the decree of the state of emergency (retrospective evaluation) and about aspects of confinement. The second questionnaire was completed after forty days of confinement and asked only about their present situation. Therefore, data were collected from three different moments: before (M1), at twenty days (M2) and at forty days (M3) of confinement.

\section{Instruments}

The questionnaire which was administered, in addition to the scales described below, contained several questions of a socio-demographic type such as age, gender, or main occupation (study or study and work).

\section{Pittsburgh Sleep Quality Index ${ }^{16}$}

We used the Spanish validation of the questionnaire, ${ }^{17}$ which consists of 24 questions, 19 to be answered by the person herself and 5 by the roommate (when applicable). The reference period according to which the participants had to answer the questions was established in the last 20 days. In order to correct the questionnaire, only the first 19 are taken into account. The first 4 (for example, at bedtime) are answered in an open format according to each person's circumstances. The other 15 are answered using a four-point ordinal scale. The questionnaire evaluates 7 different components: subjective sleep quality, latency, duration, efficiency, disturbance, medication use and daytime dysfunction. The total score of the questionnaire is acquired by adding up the scores obtained in each component once transformed and can range from 0 to 21. A score of less than 5 means "No sleep problems", 5-7 "Deserves medical attention", 8-14 "Deserves medical attention and treatment", and a score of 15 or more "Is a serious sleep problem". Therefore, the higher the score, the lower the quality of sleep. ${ }^{18}$

The questionnaire showed good internal consistency (Cronbach alpha values above.70) ${ }^{19}$ at all three moments (M1: $\alpha=, 74 ; \mathrm{M} 2: \alpha=, 77 ; \mathrm{M} 3: \alpha=, 78$ ).

\section{Adapted List of Interests ${ }^{20}$}

It is composed of 68 different interests that can be grouped into physical exercise activities (ie, cycling), relaxing activities (ie, listening to music), intellectual activities (ie, speaking and reading languages), creative activities (ie, photography), social activities (ie, playing cards), homerelated activities (ie, cleaning the house) or other types of activities (ie, going to the hairdresser). Participants had to answer whether they participated in each activity or not, and if they were interested in doing so, both before confinement (ie, first questionnaire) and at the present time. A total score was obtained by adding up all the affirmative answers and also a score for each area. Internal consistency was adequate at all three moments (M1: $\alpha=, 90$, M2: $\alpha=, 90 ;$ M3: $\alpha=, 89$ ).

\section{Ethical Considerations}

This study was approved by the bioethics committee of the University of Burgos, respecting the four Helsinki principles $^{21}$ and in accordance with Law 15/1999 of 13 December on the Protection of Personal Data. ${ }^{22}$

In addition, the participants were informed about the legal and ethical aspects derived from the research on the first page of the questionnaire, which also included the informed consent.

\section{Data Analyses}

All analyses were conducted with the SPSS Statistical Package (Version 25, IBM Corp, Armonk, NY, USA), and the level of significance was set at $p \leq 0.05$.

Firstly, goodness-of-fit tests were carried out which determined that the data were not in accordance with the normal distribution. Then, the following non-parametric analyses were performed to test the research hypotheses: Friedman test, Wilcoxon sign range test, Spearman correlation and Mann-Whitney U.

\section{Results}

\section{Descriptive Analyses}

Table 1 shows the means and standard deviations of each of the sleep dimensions, of the overall score that establishes the objective quality of sleep and the overall score of the list of

Table I Descriptive Statistics of Sleep and Interests

\begin{tabular}{|l|l|l|l|l|l|l|}
\hline \multirow{2}{*}{ Variables } & \multicolumn{2}{|l|}{ Before } & \multicolumn{2}{l|}{ 20 days } & \multicolumn{2}{l|}{ 40 days } \\
\cline { 2 - 7 } & M & SD & M & DT & M & DT \\
\hline Subjective quality & 0,67 & 0,72 & $\mathrm{I}, 29$ & 0,94 & $\mathrm{I}, 20$ & 0,84 \\
Latency & $\mathrm{I}, 23$ & 0,89 & $\mathrm{I}, 84$ & 0,96 & $\mathrm{I}, 63$ & 0,88 \\
Length & 0,67 & 0,74 & 0,56 & 0,92 & 0,57 & 0,89 \\
Efficiency & 0,2 & 0,49 & 0,37 & 0,80 & 0,47 & 0,87 \\
Disturbance & 0,96 & 0,48 & $\mathrm{I}, 13$ & 0,64 & $\mathrm{I}, \mathrm{II}$ & 0,45 \\
Use of medication & 0,15 & 0,46 & $0,1 \mathrm{II}$ & 0,48 & 0,13 & 0,58 \\
Daytime dysfunction & 0,82 & 0,72 & $\mathrm{I}, 13$ & 0,89 & $\mathrm{I}, 0 \mathrm{I}$ & 0,86 \\
Objective quality & 4,69 & 2,9 & 6,44 & 3,72 & 6,59 & 4,32 \\
List of interests & 27,85 & $7,5 \mathrm{I}$ & $\mathrm{I} 7,5 \mathrm{I}$ & 7,42 & $\mathbf{1 6 , 0 1}$ & 6,20 \\
\hline
\end{tabular}

Abbreviations: M, mean; SD, standard deviation. 
interests, in the three evaluated moments. Poor concordance is worth noticing, according to Cohen's Kappa, between the types of sleep assessment when M1 is compared with M2 $(K=0.25, p=0.0001)$, and M2 with M3 $(K=0.21, p=, 005)$, going from $62.7 \%$ of the sample in M1 without any sleep problem, $17.3 \%$ with problems deserving medical attention and $20 \%$ deserving medical attention and treatment, $29.3 \%$, $36 \%$ and $30.7 \%$, respectively, in $\mathrm{M} 2$, and $32 \%, 37.3 \%$ and $25.3 \%$, respectively, in M3. Nobody presented serious sleep disorders in $\mathrm{M} 1$, whereas there were $4 \%$ in $\mathrm{M} 2$ and $5.3 \%$ in M3\%. Therefore, the number of people with sleep disorders in M1 increased from $37.3 \%$ to $70.7 \%$ in $\mathrm{M} 2$, and $68 \%$ in $\mathrm{M} 3$.

\section{Inferential Analyses: Hypotheses}

To contrast H1 (the quality of sleep will be worse during confinement), a Friedman test was performed which indicated that $F(2,75)=4.29, p=0.12$. Since the analysis omits multiple comparisons if there is no overall statistical significance, three Wilcoxon tests were performed to test for differences between before and during confinement. The results showed that there were statistically significant differences between sleep quality of M1 and M2 $(Z=1.70, p=0.0001)$ and between M1 and M3 $(Z=1.54, p=0.005)$, but not between M2 and M3 $(Z=1.09, p=0.89)$. Sleep quality was worse in both M2 and at 40 days (M3) of confinement compared to M1 (see Table 2). Therefore, the first hypothesis is confirmed.

To contrast $\mathrm{H} 2$ (there will be more trouble sleeping during the first half hour that the person is in bed during confinement), a Friedman test was performed which showed that $F(2,75)=15.95, p=0.0001$. The results displayed that there were differences between M1 (average range $=1.69$ ) and M2 (average range $=2.21)(F(2,75)=-2.49, p=0.01)$ and M1 (average range $=1.69$ ) and M3 (average range $=2.1$ ) $(F(2,75)=-3.14, p=0.002)$, but not $(F(2,75)=0.65, p=$ 0.51 ) between M2 (average range $=2.21$ ) and M3 (average

Table 2 Ranges Resulting from the Comparison of the Three Moments of Sleep Quality

\begin{tabular}{|l|l|l|}
\hline Variables & Negative Ranges & Positive Ranges \\
\cline { 2 - 3 } & $\mathbf{N}$ & $\mathbf{N}$ \\
\hline Sleep quality MI-M2 & 42 & 26 \\
Sleep quality MI-M3 & 39 & 27 \\
Sleep quality M2-M3 & 33 & 32 \\
\hline
\end{tabular}

Abbreviations: MI, moment I before confinement; M2, moment 2, 20 days of confinement; M3, moment 3, 40 days of confinement. range $=2.1$ ). There were more sleep problems after confinement than before. The second hypothesis is also confirmed.

To contrast $\mathrm{H} 3$ (there will be more problems getting back to sleep after waking up during the night in confinement), a Friedman test was performed which indicated that $F(2,75)$ $=6.67, p=0.034$. The results showed that there were differences only between M1 (average range $=1.81$ ) and M3 (average range $=2.15)(F(2,75)=2.08, p=0.037)$, but not between M1 (average range $=1.81$ ) and M2 (average range $=2.05)(F(2,75)=1.47, p=0.42)$ nor between M2 (average range $=2.05)$ and M3 (average range $=2.15)(F(2,75)=$ $0.61, p=0.54)$. There were more problems falling asleep after waking up during the night only in M3. Therefore, the third hypothesis is partially confirmed.

Two Mann-Whitney U's were run to contrast H4 (students who work will have a better quality of sleep than those who only study during confinement). The one comparing both groups in M2 showed that $U=859.5, p=$ 0.045 , whereas in M3 it indicated that $U=835, p=0.08$. Therefore, there were only statistically significant differences in the first comparison, with a trend towards significance $(p \leq 0.1)$ in the second. Those people who study and work have a better quality of sleep (see Table 3). Therefore, the hypothesis is confirmed.

To contrast H5 (the number of activities that students will engage in according to their interests will decrease as confinement progresses), a Friedman test was performed which indicated that $F(2,75)=88.08, p=0.0001$. The results showed that there were differences between M1 (average range $=2.85$ ) and $\mathrm{M} 2$ (average range $=1.72$ ) $(F(75)=-6.9, p=0.01)$ and M1 (average range $=2.85)$ and M3 (average range $=1.43)(F(2,75)=-8.74, p=$ $0.0001)$, and a trend towards significance between M2 (average range $=1.72$ ) and M3 (average range $=1.43$ ) $(F(2,75)=-1.79, p=0.07)$. As the time in confinement progressed, students showed less activity performance. Therefore, the fifth hypothesis is confirmed.

Table 3 Average Ranges of Sleep Quality by Occupation During Confinement

\begin{tabular}{|l|l|l|}
\hline Variables & Only Study & Study and Work \\
\cline { 2 - 3 } & Average Range & Average Range \\
\hline Sleep quality M2 & 42,1 & 31,85 \\
Sleep quality M3 & 41,56 & 32,67 \\
\hline
\end{tabular}

Abbreviations: MI, moment I before confinement; M2, moment 2, 20 days of confinement; $M 3$, moment 3, 40 days of confinement. 
Finally, to contrast H6 (students who do more physical exercise and relaxing activities after 20 days of confinement will have a better quality of sleep at 40 days), two Spearman correlations were made. There was no relationship between physical exercise activities and quality of sleep at 40 days of confinement $(r(75)=-0.61, p=0.61)$, but the relationship was negative and significant $(r(75)=-.31, p=0.006)$ between relaxing activities and quality of sleep at 40 days. The result indicates the existence of a negative relationship among two of the three variables. Therefore, the sixth hypothesis is partially confirmed.

\section{Discussion}

The main objective of this study was to analyse how Covid-19 confinement had affected sleep quality and the interests of university students.

The decrease in sleep quality during the pandemic in the general population has been recently reported ${ }^{13,14,23,24}$ through cross-sectional studies, with prevalence estimates between $18.2 \%{ }^{13}$ and $57.1 \%{ }^{24}$ This study, in addition to confirming this worsening with $70.7 \%$ of the sample having sleep disorders after 20 days, proves that it remains after 40 days of confinement (68\%), showing that this affectation is not something specific, but rather prolonged over time, with the consequences for health that this implies.

Analysing some of the manifestations of this poorer quality of sleep, Wright et al, ${ }^{25}$ establishes that university students delayed their bedtime by 24 to 30 minutes depending on whether it was a holiday or a working day. According to our work, university students found more problems falling asleep during the first half hour they were in bed and, in addition, once they woke up in the middle of the night, it was harder for them to go back to sleep. Similar results were discovered by Casagrande et $\mathrm{al}^{24}$ who found greater difficulty in sleep onset. In turn, Blume et al, ${ }^{26}$ found that people tended to get up later and justified this change by the increase in flexible working hours, the increase in teleworking and the greater difficulty to differentiate whether it was a working day or a holiday, due to the number of restricted activities.

On the other hand, the number of activities that were carried out according to the person's interests also decreased, both at 20 and 40 days of confinement. One possible explanation may be simply the lack of opportunities to carry out all those activities that were done socially or in outdoor spaces; but there could be another explanation related to the adaptation to the change of such social circumstances. It could be similar to the third task to be performed in a mourning process, with the particularity that the loss during confinement would be temporary in almost all cases. According to Worden, ${ }^{27}$ this task implies that the person adapts to the new environment in which he or she lives, assuming that certain roles he or she played will not be able to be performed. During the time that this task persists, it is common for people to stop doing activities that were of interest to them before the change of circumstances, until they manage to readjust. It would be interesting to find out if confinement was experienced as a loss and, therefore, people had not yet been able to assume and reorganize their new life during confinement.

Regarding the factors that have been found to improve the quality of sleep during the pandemic, several studies find that lower levels of anxiety, depression and stress, as well as higher levels of self-esteem, positively influence. ${ }^{14,23}$ To these factors, and according to the results found, we can add the combination of working and studying, as well as doing more relaxing activities such as reading or listening to music.

Finally, we would like to point out three limitations of the research. Firstly, the sample is small, which leads to data that do not fit the normal distribution and that nonparametric, less statistically powerful tests had to be used to test the hypotheses. Secondly, that the physical activity was not evaluated with a specific questionnaire, but within the list of interests, including activities that could not be performed due to quarantine restrictions (eg, playing soccer). In future research, it would be interesting to administer a specific questionnaire on the physical activity performed, in order to have more representative information about its impact on sleep. Thirdly, although the questionnaire answered by the participants in time 1 clearly differentiated the period before the confinement from the questions referring to confinement, the retrospective data about the period before confinement could be misleading, so it would be advisable that if other deprivations of liberty occur in the future, the studies carried out use nonretrospective data.

\section{Conclusion}

In summary, it has been observed that the confinement caused by COVID-19 deteriorated the quality of sleep of university students, resulting in a reduction in the number of activities performed. However, those who dedicated time to relaxing activities such as reading or listening to music, or those who, in addition to studying also worked, 
showed a better quality of sleep, which leads us to consider the importance of the type of activities performed during the day in order to switch off from the circumstances and to sleep better at night. Moreover, these results can be useful to promote better daily routines so as to improve sleep quality, not only in students, but also in the general population.

\section{Acknowledgments}

Authors wish to thank all students who have participated in the study.

\section{Disclosure}

The authors report no conflicts of interest in this work.

\section{References}

1. World Health Organization. Coronavirus disease 2019 (COVID-19) situation report - 51.51 1-9; 2020. Available from: https://www.who. int/docs/default-source/coronaviruse/situation-reports/20200311sitrep-51-covid-19.pdf?sfvrsn=1ba62e57_10. Accessed November 9, 2020.

2. Consejo DM. El Gobierno decreta el estado de alarma para hacer frente a la expansión de coronavirus COVID-19. La Moncloa. 2020.

3. Sandín B, Valiente RM, García-Escalera J, Chorot P. Impacto psicológico de la pandemia de COVID-19: efectos negativos y positivos en población española asociados al periodo de confinamiento nacional. Rev Psicopatología y Psicol Clínica. 2020;25:1.

4. Herian MN, Desimone JA, Harms PD, Luthans F, DeSimone JA. Examining psychosocial well-being and performance in isolated, confined, and extreme environments final report. Natl Aeronaut $S p$ Adm. 2015;1-134.

5. Alberto J, Vera E. La prisionalización, sus efectos psicológicos y su evaluación. Rev Pensando Psicol. 2010;6:157-166.

6. Estébanez B, Hikikomori: jóvenes encerrados permanentemente en su habitación psicolgía y mente. Available from: https://psicologiay mente.com/clinica/hikikomori-sindrome-oriental-habitacion. Accessed November 9, 2020.

7. Wright KP, McHill A, Birks B, et al. Entrainment of the human circadian clock to the natural light-dark cycle. Curr Biol. 2013;23:1554-1558. doi:10.1016/j.cub.2013.06.039

8. Crew EC, Baron KG, Grandner MA, et al. The society of behavioral sleep medicine (SBSM) COVID-19 task force: objectives and summary recommendations for managing sleep during a pandemic. Behav Sleep Med. 2020;18:1-3. doi:10.1080/15402002.2020.1776288

9. Yadav SR, Kumar R, Kumar A, et al. Sleepless in COVID-19: how not to lose sleep in lockdowns. Monaldi Arch Chest Dis. 2020;90. doi:10.4081/monaldi.2020.1364

10. Reverter Masià J, Hernández González V, Jové Deltell M. Actividad física en adolescentes. ¿Existe evidencia científica de cómo afecta el ejercicio físico al sueño en la población adolescente? J Negat No Posit Results JONNPR. 2017;2:298-303.
11. WHO. WHO | global recommendations on physical activity for health. WHO. 2015.

12. Li G, Fan Y, Lai Y, et al. Coronavirus infections and immune responses. J Med Virol. 2020;92:424-432. doi:10.1002/jmv.25685

13. Huang Y, Zhao N. Generalized anxiety disorder, depressive symptoms and sleep quality during COVID-19 outbreak in China: a web-based cross-sectional survey. Psychiatry Res. 2020;288:112954. doi:10.1016/j.psychres.2020.112954

14. Stanton R, To QG, Khalesi S, et al. Depression, anxiety and stress during COVID-19: associations with changes in physical activity, sleep, tobacco and alcohol use in Australian adults. Int $J$ Environ Res Public Health. 2020;17:1-13. doi:10.3390/ijerph17114065

15. Favieri F, Forte G, Tambelli R, Casagrande M. The italians in the time of coronavirus: psychosocial aspects of unexpected COVID-19 pandemic. SSRN Electron J. 2020. doi:10.2139/ ssrn.3576804

16. Buysse DJ, Reynolds CF 3rd Monk TH, Berman SR, Kupfer DJ. The pittsburgh sleep quality index: a new instrument for psychiatric practice and research. Psychiatry Res. 1989;28:193-213. doi:10.1016/0165-1781(89)90047-4

17. Rico A, Fernández JA. Propiedades clinimétricas de la versión castellana del cuestionario de Pittsburgh. Vigilia-Sueño. 1997;9:81-94.

18. Luna-Solís Y, Robles-Arana Y, Agüero-Palacios Y. Validación del Índice de Calidad de Sueño de Pittsburgh en una muestra peruana. $A n$ Salud Ment. 2015;XXXI:23-30.

19. Nunnally JC, Bernstein IH. Psychometric Theory. New York: McGrawHill; 1994.

20. Kielhofner G, Neville A. The Modified Interest Checklist. Unpublished manuscript. 1983.

21. Asociación Médica Mundial. Declaración de Helsinki de la AMM principios éticos para las investigaciones médicas en seres humanos WMA - the World Medical Association. 5 de mayo del 2015 1-3; 2019. Available from: https://www.wma.net/es/policies-post/declaracion-dehelsinki-de-la-amm-principios-eticos-para-las-investigaciones-medicas -en-seres-humanos/. Accessed November 9, 2020.

22. BOE. Ley Orgánica 15/1999, de 13 de diciembre, de Protección de Datos de Carácter Oficial. Boletín of Del Estado. 1999;43088-43099.

23. Zhao X, Lan M, Li H, Yang J. Perceived stress and sleep quality among the non-diseased general public in China during the 2019 coronavirus disease: a moderated mediation model. Sleep Med. 2020. doi:10.1016/j.sleep.2020.05.021

24. Casagrande M, Favieri F, Tambelli R, Forte G. The enemy who sealed the world: effects quarantine due to the COVID-19 on sleep quality, anxiety, and psychological distress in the Italian population. Sleep Med. 2020;75:12-20. doi:10.1016/j.sleep.2020.05.011

25. Wright KP, Linton SK, Withrow D, et al. Sleep in university students prior to and during COVID-19 stay-at-home orders. Curr Biol. 2020;30:R797-R798. doi:10.1016/j.cub.2020.06.022

26. Blume C, Schmidt MH, Cajochen C. Effects of the COVID-19 lockdown on human sleep and rest-activity rhythms. Curr Biol. 2020;30: R795-R797. doi:10.1016/j.cub.2020.06.021

27. Worden WJ. El tratamiento del duelo. Ediciones Paidós; 2013. 
Nature and Science of Sleep

Dovepress

\section{Publish your work in this journal}

Nature and Science of Sleep is an international, peer-reviewed, open access journal covering all aspects of sleep science and sleep medicine, including the neurophysiology and functions of sleep, the genetics of sleep, sleep and society, biological rhythms, dreaming, sleep disorders and therapy, and strategies to optimize healthy sleep
The manuscript management system is completely online and includes a very quick and fair peer-review system, which is all easy to use. Visit http://www.dovepress.com/testimonials.php to read real quotes from published authors.

Submit your manuscript here: https://www.dovepress.com/nature-and-science-of-sleep-journal 